\title{
INTEGRATED PRODUCTION-DISTRIBUTION SYSTEMS: TRENDS AND PERSPECTIVES
}

\author{
Maryam Darvish ${ }^{1,2}$, Martin P. Kidd ${ }^{3}$, \\ Leandro C. Coelho ${ }^{1,2,4^{*}}$ and Jacques Renaud ${ }^{1,2}$ \\ Received November 30, 2020 / Accepted December 12, 2020
}

\begin{abstract}
During the last two decades, integrated production-distribution problems have attracted a great deal of attention in the operations research literature. Within a short period, a large number of papers have been published and the field has expanded dramatically. The purpose of this paper is to provide a comprehensive review of the existing literature by classifying the existing models into several different categories based on multiple characteristics. The paper also discusses some trends and list promising avenues for future research.
\end{abstract}

Keywords: Integrated logistics, production-distribution, literature review, supply chain management.

\section{INTRODUCTION}

Supply chain is viewed as a network of services and facilities engaged in raw material procurement, production and storage of finished products, distribution to reach final customers (Hugos, 2011) and also a reverse network to recapture value from used goods (Trochu et al., 2019). To date, several definitions for the term supply chain management (SCM) exist, but despite all their differences, their commonality is that supply chains coordinate and integrate interdependent activities and processes within and between companies (Carter \& Rogers, 2008; Lambert \& Enz, 2017). These processes and activities mainly include facility location, procurement, production, inventory, and distribution decisions (Stadtler, 2005; Christopher, 2016). Therefore, one would assume that these decisions are taken in an integrated fashion in a supply chain or within a

\footnotetext{
*Corresponding author

${ }^{1}$ Interuniversity Research Center on Enterprise Networks, Logistics and Transportation (CIRRELT), Québec, Canada

${ }^{2}$ Faculté des sciences de l'administration, Université Laval, Québec, Canada - E-mails: maryam.darvish@ fsa.ulaval.ca - https://orcid.org/0000-0002-0929-4864 jacques.renaud@fsa.ulaval.ca-https://orcid.org/0000-0003-3876-5378

3 Technical University of Denmark, Lyngby, Denmark - E-mail: mpki@dtu.dk - http://orcid.org/0000-0002-3680-8576

${ }^{4}$ Canada Research Chair in Integrated Logistics, Université Laval, Québec, Canada - E-mail: leandro.coelho@fsa.ulaval.ca - https://orcid.org/0000-0002-9797-1019
} 
single company. However, despite the abundance of conceptual and empirical studies on supply chain integration and coordination (e.g., Power (2005) and Mustafa Kamal \& Irani (2014)), until recently, integrated models of supply chains have been very sparse in the operations research literature. Integrated supply chain problems have become very popular recently among researchers and practitioners. Due to the vital role integrated supply chain planning plays in today's business, it is considered a source of achieving and retaining competitive advantage (Hein \& Almeder, 2016).

Several forces have been revolutionizing supply chains. On the one hand, new and emerging localization, communication, and real-time decision-making technologies are reshaping supply chains. On the other hand, customers are becoming increasingly demanding and expect fast and flexible deliveries at a low cost. The increasing awareness of customers toward sustainability has also become a significant motivation for the transformation of supply chains. Another critical driver of this change is digitization and data analytics. All this has led to more sophisticated decision-making processes, which require fast and efficient actions of modern supply chains. Companies' success in the new era is not defined by how much data they have access to and how much data they can generate, but by how they can make better data-driven decisions. The SCM transformation has also been reflected in the Operations Research (OR) literature. Speranza (2018) summarizes the most pertinent supply chain trends in OR as: 1. systematic focus, 2. information synthesis, 3. collaborative relationship, 4. demand shaping, 5. transformational agility, 6. flexible network integration, and 7. global optimization.

The primary focus of this paper is on collaborative relationship, network integration, and global optimization. While Speranza (2018) provides a general overview of trends in SCM, focusing on the global optimization trend, in this paper, we overview the existing literature on two important decisions of any supply chains: production and distribution. Therefore, the purpose of this literature review is to provide a guideline on the current status of this broad field of OR, to identify current research trends, and suggest directions for future research, including holistic supply chain planing, supply chain optimization, sustainable supply chains, real world applications, and developing efficient solutions algorithms.

The rest of the paper is organized as follows. In Section 2, we provide an overview of integrated versus sequential approaches to supply chain decision making. Moreover, the most popular integrated optimization problems are introduced. We present a general overview of the productiondistribution literature in Section 3. In Sections 4 and 5, papers considering single and multiple products are reviewed, respectively. Discussions on the state of the literature and directions for future research can be found in Section 6. Finally, we conclude the paper in Section 7.

\section{A GENERAL OVERVIEW}

In this section, we present a general overview on sequential versus integrated supply chain functions and problems and we review the most known integrated supply chain problems. 
Supply chain planning includes all three levels of strategic, tactical, and operational decisions. Simultaneous optimization of all these decisions by integrating them into a single model is a complex and challenging task. Therefore, traditionally, each decision was treated separately from the others, meaning that management was performed in silos, as shown in Figure 1. Since these decisions were studied separately, each had a dedicated field of research in the OR literature. From a practical point of view, the planning processes relied mainly on spreadsheets and localized data (Bean et al., 2005). Even for the internal planning, each department of the company has been using its own databases, methods, and spreadsheets. In several of our recent industrial collaborations, we have observed how each department (finance, production, sales, warehousing and marketing, for example) relies on its spreadsheet to forecast demand and how these demand forecasts, which are the basis of all their decisions, are not communicated to other departments of the same company.

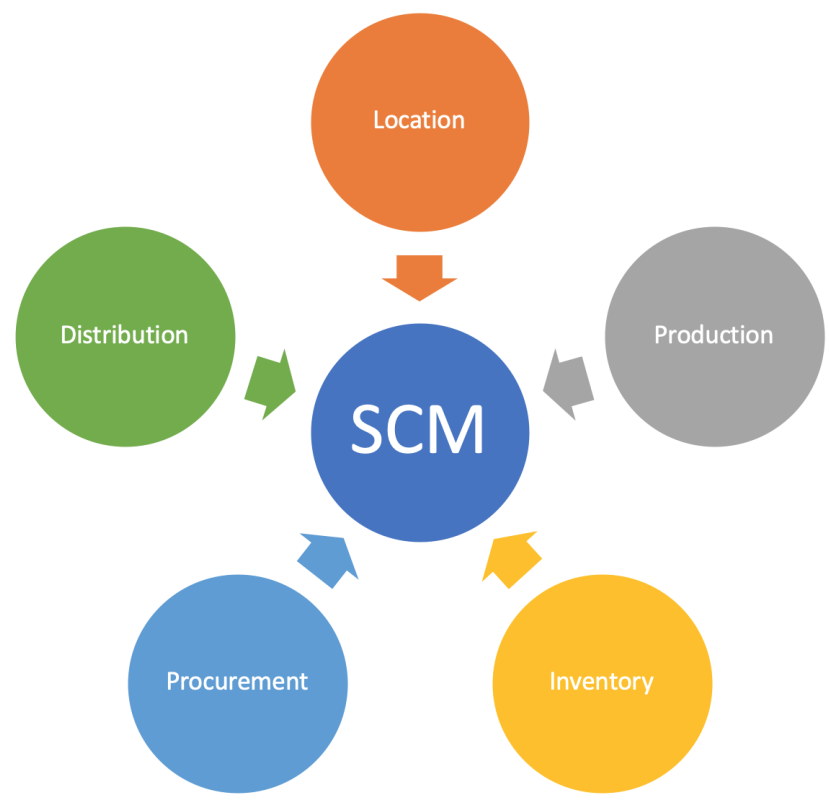

Figure 1 - Supply chain decisions.

An integrated SCM considers several decisions simultaneously, as depicted in Figure 2. Jointly optimization of these supply chain planning decisions has been such a complex and difficult task that each decision had to be treated separately. Therefore, the problem was decomposed into smaller and easier to solve subproblems. For example, location, lot sizing, and distribution have traditionally been solved independently from one another, e.g., Erlenkotter (1978); ReVelle \& Laporte (1996), Florian et al. (1980); Barany et al. (1984); Maes et al. (1991), Desrochers et al. (1992); Gendreau et al. (1994) and Taillard et al. (1997). Hence, using a sequential hierarchical approach was prevalent. In this approach solutions obtained from one decision level needs to 
be passed and imposed to the next level. The major problem with the sequential/hierarchical decision-making approach is that when decisions are made in silos, all the interactions between them are lost. Given that, decisions in a supply chain have mutual impacts on one another and should be solved simultaneously, decision making in silos will result eventually in suboptimality (Vogel et al., 2017).

Although decisions from different supply chain levels can be integrated, the main contributions rely on production and distribution integration. In any manufacturing industry, production, and distribution encompass the pivotal roles as these are costly operations. Moreover, these two decisions balance the supply and demand by managing the inventory level. How much, and when to produce and store, when, how much, and how to distribute products to customers are among the most important decisions in any supply chain.

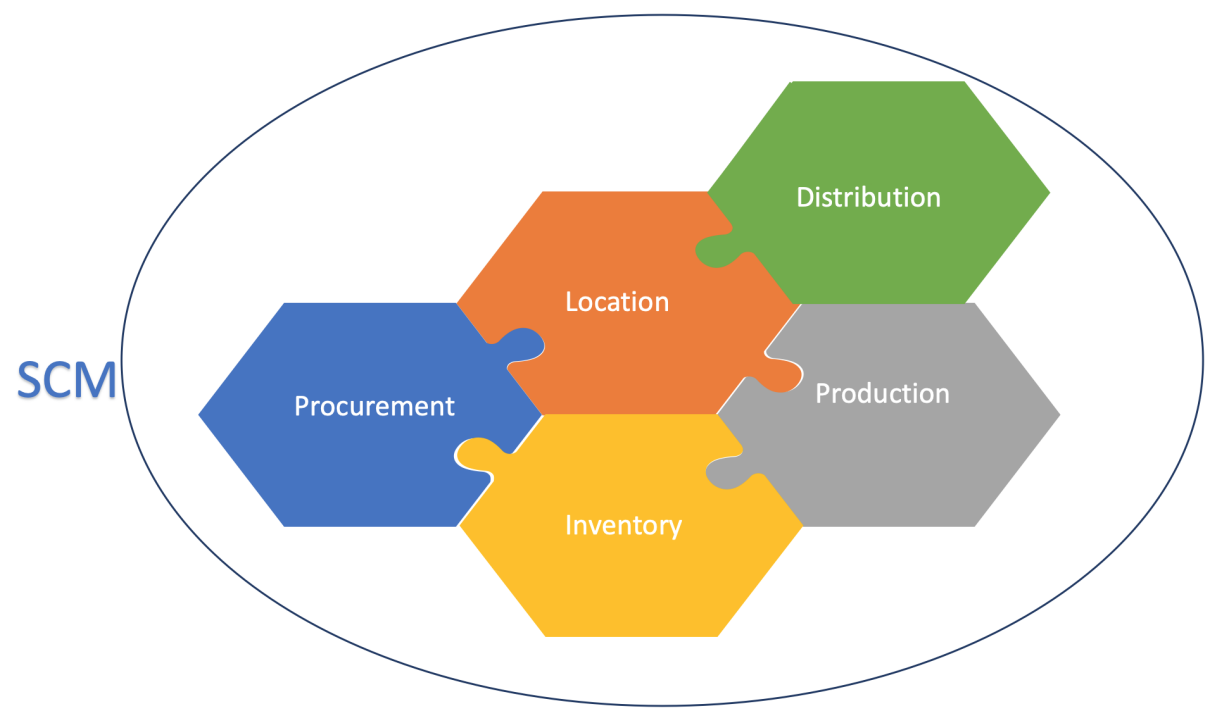

Figure 2 - Integrated supply chain planning.

\subsection{Classical integrated problems}

It is common for the integrated supply chain problems observed in the literature to combine at most two functions. Due to their nature, operational level decisions have always been good targets for integration purposes. Literature review papers, published to date, have attempted to provide a comprehensive overview of these integrated problems (e.g., Coelho et al. (2014); Adulyasak et al. (2015); Drexl \& Schneider (2015)). In what follows, we present the classical integrated problems and we refer the interested readers to the respective publications for each class of problem. In Table 1, we present the well-studied integrated supply chain planning models, adapted from the work of Adulyasak et al. (2012). 
Table 1 - Integrated supply chain planning.

\begin{tabular}{l|cccc}
\hline Problems & Location & Production & Inventory & Routing \\
\hline Location-Routing Problem (LRP) & $\checkmark$ & & & $\checkmark$ \\
Location-Inventory Problem (LIP) & $\checkmark$ & & $\checkmark$ & \\
Lot Sizing Problem (LSP) & & $\checkmark$ & $\checkmark$ & \\
Inventory-Routing Problem (IRP) & & & $\checkmark$ & $\checkmark$ \\
Production-Routing Problem (PRP) & & $\checkmark$ & $\checkmark$ & $\checkmark$ \\
\hline
\end{tabular}

Location-routing problem (LRP): being closely related to the supply chain network design, facility location planning (FLP) has long been regarded as a critical strategic issue in the literature (Laporte et al., 2019). It deals with decisions such as establishing a new facility, relocating the existing ones, or any capacity expansion planning (Melo et al., 2006). In FLPs, a set of alternative locations are available to serve geographically dispersed customers, and the goal is to select locations such that the cost/time of reaching customers is minimized (Melo et al., 2009). Literature reviews published on the FLP classify models and solution algorithms and provide a comprehensive picture for a large variety of FLPs (e.g., Francis et al. (1983); Brandeau \& Chiu (1989); Owen \& Daskin (1998); Klose \& Drexl (2005); Snyder (2006); Şahin \& Süral (2007); Melo et al. (2009); Farahani et al. (2012, 2014); Schneider \& Drexl (2017)). Due to the strategic nature of location decisions, considerable capital investment as sunk costs has been associated with these decisions; therefore, their integration with other tactical or operational decisions was less prevalent in the integrated optimization literature (Nagy \& Salhi, 2007). However, joint efforts such as the one between Proctor \& Gamble and Walmart, to manage the distribution flows efficiently and collaboratively have become more common (Amiri, 2006) in practice, to the extent that dynamic selection of partners in supply chains is identified as one of the new trends and research opportunities in the SCM (Speranza, 2018). Having been adapted to the new business environment's reality, location decisions can now enjoy more flexibility, so they should be revised periodically, and hence, they can now be easily combined with other tactical/operational level decisions. Even if considered as a long-term decision, the facility location is interrelated with other supply chain decisions, particularly transportation activities (Drexl \& Schneider, 2015). Boventer (1961) recognizes the relationship between transportation costs and location rental fees and introduces location-routing problems (LRPs) as the combination of facility location and routing decisions. Several papers such as Nagy \& Salhi (2007); Prodhon \& Prins (2014); Drexl \& Schneider (2015); Darvish et al. (2019); Schmidt et al. (2019); Almouhanna et al. (2020) discuss different variants and extensions of the LRP. In the LRP, the questions of which facilities to select, which customers to visit, and in which order they should be served are answered (Drexl \& Schneider, 2015). The objective is to minimize the total cost of locating facilities and distributing products.

Location-inventory problem (LIP): the LIP combines the strategic location decisions with operational inventory management. The literature deals with inventory and location problems separately. First, the location and number of distribution centers (DCs) or warehouses are decided 
by solving a facility location problem and then by fixing these decisions, the optimal inventory replenishment policies are determined (Daskin et al., 2002). By decomposing the LIP into two separate problems, all the interrelated costs are ignored; this approach becomes questionable, especially in dealing with uncertain demands (Shen et al., 2003). Farahani et al. (2015) provides a review of the models that jointly consider facility location decisions and inventory management problems. In the LIP, the questions of which facilities to select and how much inventory keep at each facility are answered, the objective to minimize the total facility location and inventory holding costs.

Lot sizing problem (LSP): as a fundamental and challenging problem in production planning, the LSP integrates production and inventory decisions and deals with the trade-offs between production and storage costs (Karimi et al., 2003). The objective is to minimize the total cost of production, setup, and inventory (Jans \& Degraeve, 2007). Since the seminal paper of Wagner \& Whitin (1958), several studies have investigated the LSP. Florian et al. (1980) prove that the single-product capacitated problem is NP-hard, and Maes et al. (1991) show that finding a feasible production plan for a capacitated production system with no setup cost is an NP-complete problem; even a multi-plant, uncapacitated lot-sizing problem is NP-complete (Sambasivan \& Schmidt, 2002). Numerous reviews of the literature (e.g., Karimi et al. (2003); Brahimi et al. (2006); Jans \& Degraeve (2007, 2008); Robinson et al. (2009); Buschkühl et al. (2010); Glock et al. (2014); Axsäter (2015)) have provided an overview of variants, models, and algorithms for LSPs.

Inventory-routing problem (IRP): as the name indicates, the IRP is the integration of inventory management and routing decisions. An indispensable part of many integrated supply chain models entails the delivery/transportation decisions. On the one hand, in most industries, transportation cost is the major component of the total logistics cost (Boudia et al., 2007). On the other hand, the ever-rising transportation costs and increasing customer sensitivity to lead time have become the salient reasons behind the supply chain literature's emphasis on transportation cost reduction and performance increase. The road-based transportation methods mentioned in different existing integrated optimization problems (Coelho et al., 2016) could be classified into two broad categories of direct shipment and routing decisions. A very well-known and wellresearched area in distribution and transportation planning is the vehicle routing problem (VRP) (Toth \& Vigo, 2014). The VRP focuses on designing vehicle routes to make deliveries to customers in each period. Several papers review variants, models, and algorithms of the VRP (e.g., Laporte (1992); Eksioglu et al. (2009); Laporte (2009); Pillac et al. (2013); Lahyani et al. (2015); Coelho et al. (2016); Koç et al. (2016); Psaraftis et al. (2016); Ritzinger et al. (2016)). The IRP first appeared in the literature as a variant of the VRP (Coelho et al., 2014). The reviews on the IRP of Campbell et al. (1998); Moin \& Salhi (2007); Andersson et al. (2010), and Coelho et al. (2014) provide an exhaustive overview of its variants, applications, models and formulation, and solution methods. In the IRP, the questions of how much inventory to keep at each center, which customers to serve, and visiting order of these customers are to be answered. The objective is to minimize the total cost of inventory and transportation. 
Production-routing problem (PRP): the PRP is an integration of the IRP with production decisions (Coelho et al., 2014) or equivalently, the LSP with the VRP (Adulyasak et al., 2015). The most recent reviews on the PRP (Adulyasak et al., 2015; Díaz-Madroñero et al., 2015) thoroughly investigate the various solution techniques, formulations, applications, and classifications of the problem. The PRP determines how much to produce in each period, how much inventory to keep at each facility, and which customers to serve and in which order. The PRP jointly minimizes the production (setup and variable), inventory, and transportation costs. It belongs to the vast class of integrated production-distribution problems.

The integration of production and distribution decisions is an important and widely studied area of the supply chain literature, as according to Chen (2004), production and distribution are the most critical operational decisions of any supply chain. To better understand, classify the broad integrated production-distribution literature, and provide directions for future research, in what follows, we review state of the art on the topic and discuss their assumptions, main problems, methods, and results. In this work, we also review studies in which the strategic decisions, such as facility location, are simultaneously optimized with short-term and operational level decisions, such as transportation and distribution.

\section{INTEGRATED PRODUCTION-DISTRIBUTION PROBLEMS AND CASES}

Both production and distribution problems are very well-studied in the operations research literature. The integrated production-distribution problems has also received much attention over the last decade. However, there is a confusion in the literature on how the integrated problem should be called. The difference in what to call the integrated production-distribution problem stems from the variants of the production and distribution decision being considered. In some cases, despite the differences in what the integrated problems are called, they tackle the same issues. Chandra \& Fisher (1994) deal with production scheduling and distribution problem (PSD). The integration of production and routing is called the production-inventory-distribution-routing problem (PIDRP) in Bard \& Nananukul (2009b); Lei et al. (2006) and Bard \& Nananukul (2010), it is also considered as integration of the inventory-routing problem with the production planning problem and called integrated production-distribution problem (IPDP) by Armentano et al. (2011) and Boudia \& Prins (2009) or the PRP by Absi et al. (2014), Adulyasak et al. (2012), and Adulyasak et al. (2015). Karaoğlan \& Kesen (2017) study the integrated production and transportation scheduling problem (PTSP). The lot-sizing problem with production and transportation (LSPT) is studied in Hwang \& Kang (2016), the same problem is called operational integrated production and distribution problem (OIPDP) in Belo-Filho et al. (2015). Finally, when location decisions are incorporated into the production-distribution model, the problem becomes a production-distribution system design problem (PDSDP) (Elhedhli \& Goffin, 2005). In any case, we observe that the integration of production and distribution is a topic present in two distinct streams of research. One deals with integrated facility location and distribution planning decisions and the other integrates lot-sizing problem with distribution decisions. Looking at the cost structure of the objective function in the integrated facility location and the LSP in single eche- 
lon, single-product/period models, the distinction between the two streams becomes less evident. By putting the common elements of both objective functions aside, i.e., transportation, inventory handling, and variable production costs, in both streams a binary decision variable is present to decide whether a product is produced in a plant. This decision is called facility location allocation in the FLP and setup decision in the LSP.

As of now, a number of reviews on the coordination and integration of production and transportation decisions exist. Sarmiento \& Nagi (1999) survey integrated production and distribution systems, Mula et al. (2010) review mathematical programming models for supply chain production and transport planning, Chen (2010) and Meinecke \& Scholz-Reiter (2014) review integrated production and outbound distribution scheduling (IPODS), and the integrated production-distribution planning is reviewed in Fahimnia et al. (2013).

In this literature review paper, we examine and classify the integrated production-distribution problem. Our criteria for selecting the studies are that both production (either variable or fixed setup) and transportation costs must be present in the objective function. In most studies, production and distribution decisions indirectly lead to the incorporation of inventory decisions into the models.

Generally, the common assumptions of most papers dealing with the integration of production and distribution are as follows. All products can be produced in any of the plants (multifunctional plants). When routing is the delivery method, each customer can be visited at most once per day and a fleet of homogeneous vehicles with limited capacity is considered. The demand cannot be split, and no shortage, stockouts, or backlogging is allowed. Finally, transfer between sites is not allowed. The cost functions are often linear. However, fixed-charge and general concave cost structures are also considered in some studies. In what follows, when economies of scale are present, we call the cost function concave. Unless otherwise specified, these are the assumptions of the problems studied here.

The following research papers are beyond the scope of this literature review. Those papers that do not present any mathematical models to solve optimization problems. For this literature review, integrated production-distribution models that include production scheduling are out of the scope of this study. In a multi-stage production system, products move from one stage to the next, and therefore, production scheduling is required to optimize the system. In line with our argument before on the similarities of facility location and lot-sizing problems, we consider facility location as a characteristic of the model only if a distinct variable is defined to indicate whether a facility is operational in a period or to select a/several facility(ies) among a set of available ones.

We first organize our revision around two broad categories of single versus multi-product models and then based on either the distribution method (for single-product) or number of echelons (for multi-product). Several other factors are also considered. A general overview of our classification is depicted in Figure 3. Our decision for this classification is first based on the number of papers we cited for each category and then the similarities of the approaches considered. 


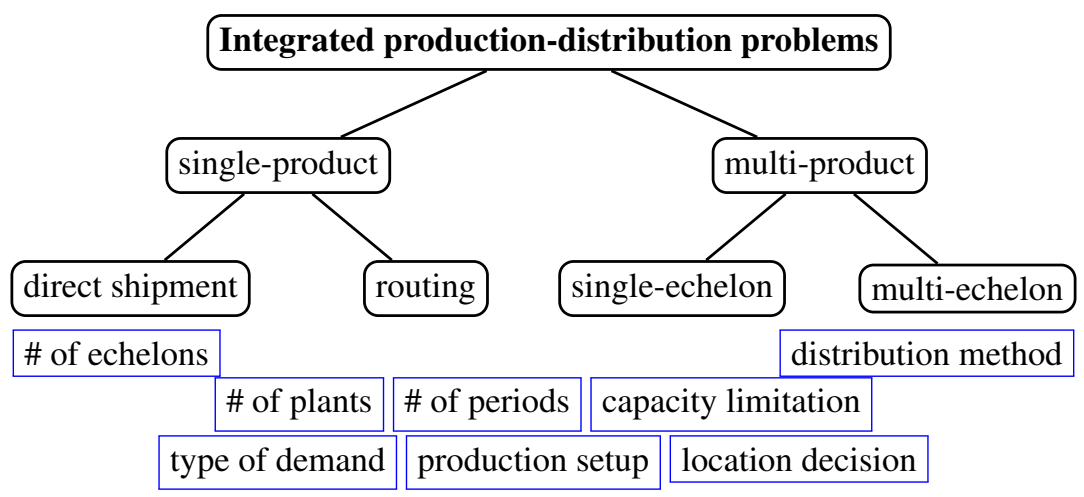

Figure 3 - Classification criteria for integrated production-distribution problems.

Variants of production-distribution models with single-product are presented in Section 4 and models that consider multiple products are reviewed in Section 5.

\section{SINGLE-PRODUCT PRODUCTION-DISTRIBUTION MODELS}

In this section, we review integrated production-transportation models for single-product problems. To better analyze their variants and characteristics, we divide them into two categories depending on the delivery method: direct shipment or routing.

\subsection{Direct shipment decisions}

To formulate the production-distribution planning problem, several authors used a capacitated minimum-cost network flow problem (e.g., van Hoesel et al. (2005); Ekşioğlu et al. (2006)). van Hoesel et al. (2005) proposed a dynamic programming (DP) algorithm to study different transportation and inventory holding cost structures in their multi-echelon integrated problem and Ekşioğlu et al. (2006) a primal-dual based heuristic to solve an integrated problem with multifunctional plants. All costs in van Hoesel et al. (2005) are concave but in Ekşioğlu et al. (2006) only transportation costs are concave where production and setup cost vary from one plant to another as well as from one period to the next. Ekşioğlu et al. (2006) argued that their problem is a special case of the FLP and an extension of the classical LSP, as the facility selection decision is also present in the model. Hwang et al. (2016) reduced the complexity of the algorithm proposed in van Hoesel et al. (2005) by utilizing only the information on the aggregated production quantities and considering only those periods in which transportation occurs. A concave transportation cost consisting of fixed and variable shipment costs, and a linear holding cost function were assumed. Later Hwang \& Kang (2016) considered a stepwise transportation function for a production-distribution problem in which backlogging is allowed. They further improved the $\mathrm{O}\left(T^{3}\right)$ algorithm of Hwang et al. (2016) and reduced its complexity to $\mathrm{O}\left(T^{2} \log \mathrm{T}\right)$ where $T$ is the number of periods. 
The single-sourcing suggests that the customer demand during the whole planning horizon is fulfilled from the same facility and cannot be split among different facilities. Ahuja et al. (2007) studied a single-sourcing integrated problem in a dynamic environment in which production, inventory, throughput, and several product perishability constraints are considered. Their problem is formulated as a nonlinear assignment problem and is solved by a greedy heuristic where later a very-large-scale-neighborhood (VLSN) search method improves the greedy solutions.

Some authors considered the integrated production-distribution problem as integration of the LSP with production and transportation (e.g. Hwang (2010); Akbalik \& Penz (2011)) and some others as the integration of facility location and production planning decisions (e.g., Romeijn et al. (2010); Sharkey et al. (2011)).

Hwang (2010) used a stepwise cost function for transportation considering economies of scale for shipment, and consequently production. They assumed unlimited number of vehicles and concave production cost in their problem. They discussed inventory systems with and without backlogging allowed. The goal of the paper by Akbalik \& Penz (2011) is to compare inventory the just-in-time and time window policies. Therefore, they incorporated delivery time windows into their model. Under the just-in-time policy, delivery quantities to customers are fixed to the demand but with the time window policy, deliveries can be aggregated and delivered before the due date. In their model, costs change over time and a fixed transportation cost per vehicle is assumed. Their results showed that the time window policy has a lower cost. To solve the problem, they proposed a DP algorithm. They compared its performance against the one of the mixed integer linear programming (MILP) and concluded that the DP always outperforms the MILP, even for large size instances.

Romeijn et al. (2010) introduced the idea of generalizing the LSP by integrating it with facility location decision (Liang et al., 2015). Therefore, the objective function considered minimizes location, production, inventory, and transportation costs. They developed a new approximation method for cases with special production and inventory cost structures and seasonal demand patterns. Similar to the problem studied in Romeijn et al. (2010), Sharkey et al. (2011) integrated location and production decisions. They applied a branch-and-price algorithm to solve their single sourcing integrated problem. Their results highlighted the potential benefits of this integration. They concluded that the proposed branch-and-price algorithm works better on the cases where the ratio of the number of customers to the number of plants is low. Senoussi et al. (2018) studied a supply chain consisting of one plant and several retailers, where the plant is located far from the customers. A total cost had to be minimized which consists of production setup cost, fixed vehicle cost, and fixed customer visiting cost, and the inventory costs at the plant and customers. They proposed several genetic algorithm (GA) based heuristics to solve large size instances of the problem.

Recently, the context has become even richer. Darvish et al. (2016) introduced a rich problem which integrates production and direct shipment decisions. They considered a delivery due date for shipments, which can be distributed from any of the selected facilities. They used a branchand-bound approach to solve and assess the cost-service level trade offs. Gruson et al. (2019) 
compared several formulations for what they call a three-level (plant-warehouse-retailer) lot sizing and replenishment problem with a distribution structure. No transshipment between warehouses or retailers was considered in their model. Inventory can be held at all three levels of the supply chain at a cost. Their results showed how the echelon stock reformulation suits capacitated instances the best while the multi-commodity formulation worked the best for uncapacitated ones.

Table 2 provides a summary of these studies. It seems the DP is a popular solution algorithm for the problems in this category.

\subsection{Routing decisions}

Integrated production and routing decisions is called by the PRP in the literature, for which heuristic approached are mainly used. The problem is of practical relevance, a real-life application is presented in Schenekemberg et al. (2020).

In most papers, a homogeneous fleet of vehicles is considered but Lei et al. (2006) studied the PRP with a heterogeneous fleet of vehicles. They proposed a two-phase heuristic approach to solve the problem. By relaxing the routing decisions In the first phase, they solved the problem considering direct shipments. For the second phase, they proposed a heuristic to deal with the routing decisions.

The PRP with capacity constraints is studied in Boudia et al. $(2007,2008)$ and Boudia \& Prins (2009). In their application, customers are served at most once a day based on a first-in-first-out (FIFO) policy and by a limited fleet of capacitated vehicles. Customers cannot receive a late service, however, if the capacity permits, their demand can be fulfilled in advance. Although the inventory capacity at the plant and customers is limited, the holding cost at the customer is negligible compared to that of the plant. Boudia et al. (2007) proposed a greedy randomized adaptive search procedure (GRASP) to solve the PRP. However, in order to change production and delivery days for some of the demands a local search method was suggested and to reinforce the combination either a reactive mechanism or a path relinking was added. Boudia et al. (2008) proposed two greedy heuristics followed by two local search procedures to solve the problem. The same problem was solved using a memetic algorithm with population management (MA|PM) in Boudia \& Prins (2009). Their memetic algorithm yielded better results than the GRASP, and showed 23\% saving in costs compared to the classical hierarchical approach. The same problem is addressed in Bard \& Nananukul (2009a,b, 2010), in which a single plant serves a set of customers over a multi-period time horizon. The demand is satisfied either from the inventory held at the customer or daily distribution of the product. Two cases were considered for the distribution: to fulfill the demand of the day by vehicle routing or by replacing routing with allocation and aggregated vehicle capacity constraints (Bard \& Nananukul, 2010). Bard \& Nananukul (2009a) solved the problem with a reactive tabu search which is followed by a path relinking procedure to improve the solution. Compared to the results obtained by Boudia et al. (2007), Bard \& Nananukul (2009a) achieved slightly better solutions. Bard \& Nananukul (2009b) used a branch- 


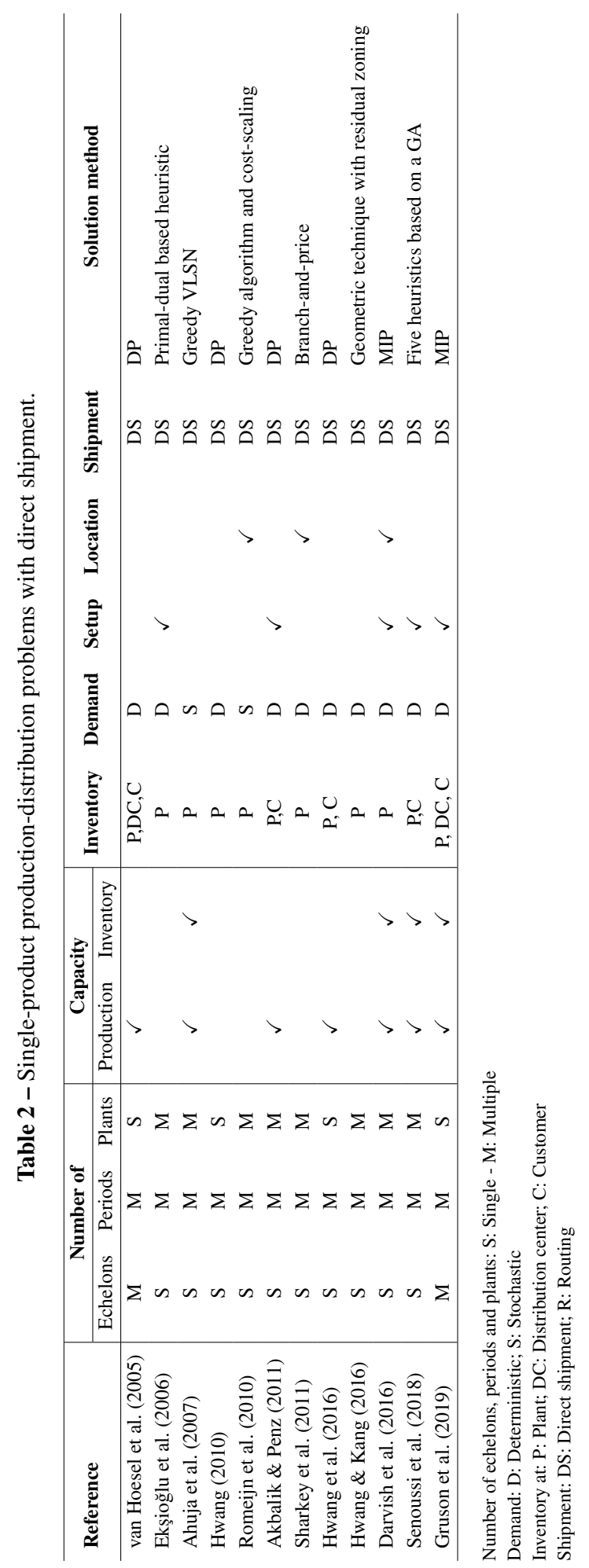


and-price algorithm and compared several heuristics for the IRP in the context of the PIDRP. To take advantage of the efficiency of a heuristic and accuracy of the branch-and-price, Bard \& Nananukul (2010) improved their former method by proposing a hybrid algorithm combining exact and heuristic methods within the branch-and-price framework. Within 30 minutes of run time, the algorithm was able to find optimal solutions only for instances with up to 10 customers, two periods, and five vehicles. Moreover, the obtained lower bounds were not strong.

Several strong reformulations and inequalities to strengthen these reformulations are presented in (Ruokokoski et al., 2010). They considered a single uncapacitated vehicle and as in Bard \& Nananukul (2010), the maximum level (ML) inventory policy was used for the quantities delivered to each retailer. Their results highlighted the cost saving benefits of the coordinated approach compared to the uncoordinated one. The proposed branch-and-cut algorithm could solve instances with up to 80 customers and eight periods, but solving larger instances was still considered a challenge. This method is also used in Archetti et al. (2011) to compare the ML and order-up to level (OU) inventory policies in the PRP context. The demand is delivered to the customers using an unlimited fleet of capacitated vehicles. They concluded that the ML policy outperforms the OU in short time horizons, but with an increase in the number of periods, the difference between the costs obtained from these two policies also decreases. However, within two hours of execution, the proposed branch-and-cut approach could not provide optimal solution for all instances. Instances generated in (Boudia et al., 2007) and (Archetti et al., 2011), are the benchmark instance sets of the PRP literature.For example, Solyalı \& Süral (2017) used a multiphase heuristic to solve a single echelon PRP with production and inventory capacities. They evaluated the performance of their proposed heuristics on these benchmark instances. they concluded that although the multi-phase heuristic can find new best solutions for $65 \%$ of instances, for larger instances, a better solution comes at the cost of higher computation time.

The first comparative study of the solutions algorithms for the PRP appeared in (Adulyasak et al., 2012). They compared the performance of the adaptive large neighborhood search (ALNS) heuristic against the GRASP (Boudia et al., 2007), MA|PM (Boudia \& Prins, 2009), reactive tabu search (Bard \& Nananukul, 2009a), tabu search with path relinking (Armentano et al., 2011), and the branch-and-cut approach proposed of Archetti et al. (2011). The proposed heuristic in (Adulyasak et al., 2012) outperformed all the former methods.

Later Absi et al. (2014) proposed a two-phase iterative heuristic approach for the PRP which outperformed the ALNS proposed by Adulyasak et al. (2012). They applied this decomposition method to solve the PRP considering a limited fleet of capacitated vehicles and an ML inventory policy. Their decomposition method addressed the lot sizing decisions in the first phase and determined the routing ones in the second phase. They concluded that while the second phase outperforms all the existing methods in shorter running time, developing fast heuristics to yield good results for the lot sizing in the first phase still remains a challenge.

Adulyasak et al. (2014) considered the PRP with both ML or OU policies. A main difference between their model and that of Archetti et al. (2011) is that products can be delivered to customers on the same period as the demand happens, and there is no need to wait until products 
are replenished in the facility. Using a single core and within two hours of execution, instances with up to three periods and three vehicles, and up to 25 customers were solved to optimality. Later, and for the first time in the literature, the authors addressed the PRP with demand uncertainty in Adulyasak et al. (2015). They proposed and compared the branch-and-cut algorithm with Benders decomposition method to solve the two-stage and multi-stage stochastic PRP.

To summarize, as indicated in Table 3, only Adulyasak et al. (2015) considered the demand to be stochastic. Except for van Hoesel et al. (2005), models mainly addressed a single plant-retailer echelon. In a few papers, the model did not consider the fixed or setup cost of production but they assumed the production cost to be a function of the quantities produced. Exact methods (mostly DP) and metaheuristics are exploited when the direct shipment is the delivery method. Prior to 2010, the common solution approach to tackle the PRP was metaheuristics, however, matheuristics are more common since they proved to be better in terms of efficiency and performance. We also notice that when the distribution method is direct shipment more variants of the production problem are considered. However, in the PRP context the focus has mainly been on finding faster and more efficient solution algorithms. Therefore, the majority of the PRP studies compare their results and performance of the algorithms with the already existing methods from the literature.

\section{MULTI-PRODUCT PRODUCTION-DISTRIBUTION MODELS}

In this section, we present the integrated production-distribution models with multiple products. The number of publications in this category is less than the ones with single-product models. Obviously, adding multiple products to models makes them more difficult to solve, therefore, in this section fewer papers consider routing as the shipment method. Here, we first present those studies that consider only one echelon in the model, mostly considering a set of plants and customers. Then, multi-echelon problems are surveyed.

\subsection{Single-echelon models}

A few papers formulate and solve the multi-product PRP. This problem is studied for the first time by Chandra \& Fisher (1994) where an unlimited fleet of vehicles and storage capacity limits were assumed. No inventory holding cost was considered at the plant. They solved the PRP with a local improvement heuristic and showed how integrating production and distribution decisions leads to 3-20\% cost savings. The value of integration is also highlighted in Fumero \& Vercellis (1999). In most PRP papers, partial customer demand delivery is prohibited, no advanced delivery is allowed, and the transportation cost is mainly a function of the distance. These assumptions did not hold in Fumero \& Vercellis (1999). Transportation costs were defined based on both loads and distances while considering a fixed cost per vehicle. To solve this PRP with homogeneous and capacitated vehicles, Fumero \& Vercellis (1999) applied a Lagrangian relaxation approach. The value of integration having been proven, the literature has focused on developing intricate methods to solve the problem. Armentano et al. (2011) developed a tabu search with path relinking approach to solve a PRP with a fleet of identical vehicles. First, they tested the performance 


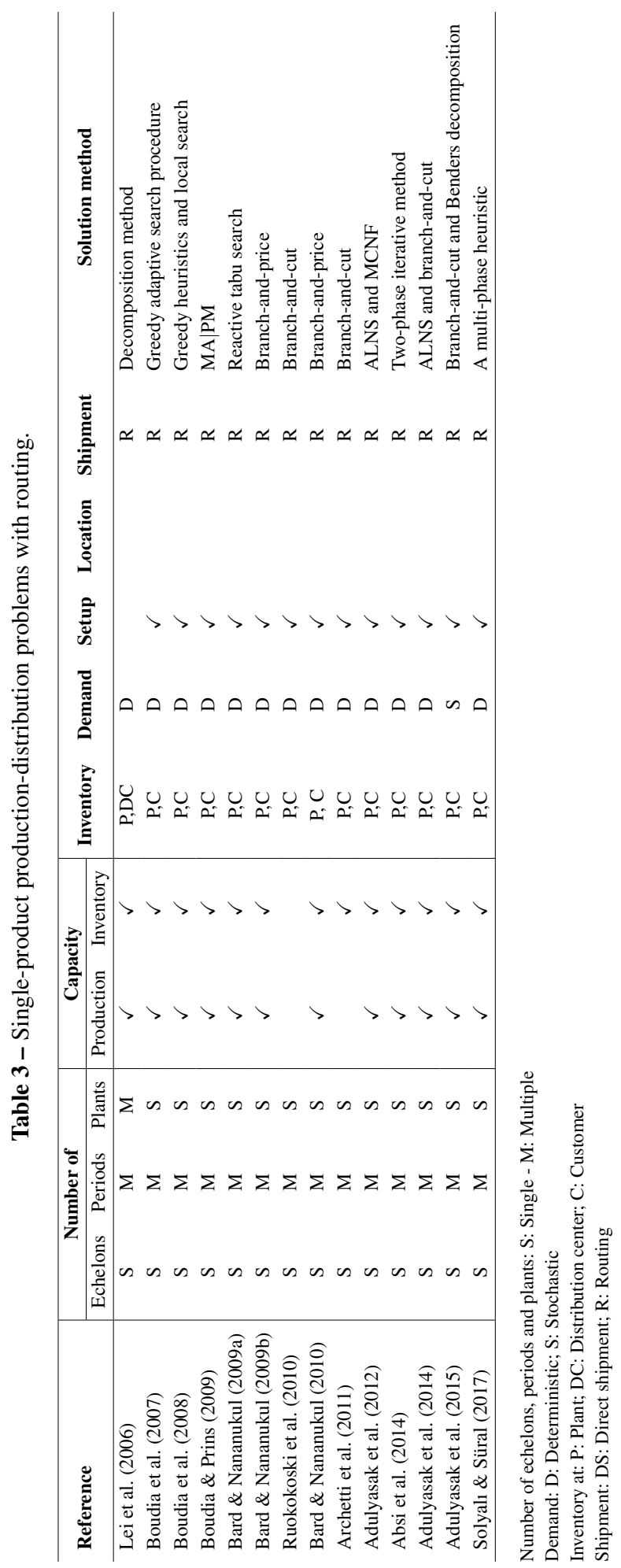


of the proposed method on benchmark instances from the literature for the PRP with single product of Boudia et al. (2007). They showed the superiority of their proposed approach to the MA|PM (Boudia \& Prins, 2009) and reactive tabu search (Bard \& Nananukul, 2009a) methods. Then, they generated instances for the multi-product PRP to compare the performance of their proposed solution algorithm to tabu search. They concluded that although tabu search with path relinking requires more execution time, it always obtains better solutions. Finally, Brahimi \& Aouam (2016) introduced the backordering into the PRP context. To solve this problem, they used a hybrid of a decomposition relax-and-fix method with a local search heuristic.

The solutions algorithms and variants of the integrated production-distribution problems with direct shipment as the distribution method are more diversified. In some studies a profit maximization objective function is considered. For example, Jolayemi \& Olorunniwo (2004) introduced an integrated production-distribution problem with the possibility of capacity expansion. Therefore, if plants face a lack of sufficient resources, subcontracting will be allowed. Beside this new dimension, Jolayemi \& Olorunniwo (2004) introduced a reduced model, i.e., a smaller MILP problem, and showed how both models (full-size and reduced) led to the same results. Park (2005) proposed a two-phase heuristic to solve another profit maximization integrated production-distribution problem. The considered an OU inventory policy and the possibility to run out of stock. To solve the problem, the author tries first to come up with production and distribution plans, and later to improve these plans by consolidating deliveries. The results revealed the advantage of using an integrated approach over a decoupled one. However, the author concluded that the integrated approach leads to more profit when vehicle capacities are small but fixed cost of vehicles, unit cost of stockout, and production capacity are relatively high. Melo \& Wolsey (2012) studied a similar problem but they solved it using a hybrid heuristic.

Decomposition methods are also popular in solving the integrated production-distribution problems. The multi-product version of the problem studied in Ekşioğlu et al. (2006) is solved by a Lagrangean decomposition heuristic in Ekşioğlu et al. (2007). Nezhad et al. (2013) applied Lagrangian relaxation heuristics to solve an integrated production-distribution problems with uncapacitated and single-source plants. This is one of the few papers in which only one period is considered. Although they solved a location problem in a sense that the model assigns customers to plants, they do not impose any costs for utilizing a plant in a period (location costs). The only fixed cost incurred in the model remained the setup cost of production.

Liang et al. (2015) extended the model presented in Romeijn et al. (2010) by allowing backlogging. They proposed a hybrid column generation and relax-and-fix method. Th latter provides lower bounds and the former yields upper bounds for the problem. Comparing their results to the ones from a commercial solver, their approach outperforms the commercial solver in obtaining better lower and upper bounds and unlike the commercial solver, it is not sensitive to the number of facilities as a measure of the instance size.

A summary of the integrated production-distribution models with multiple products and single echelon is presented in Table 4. 


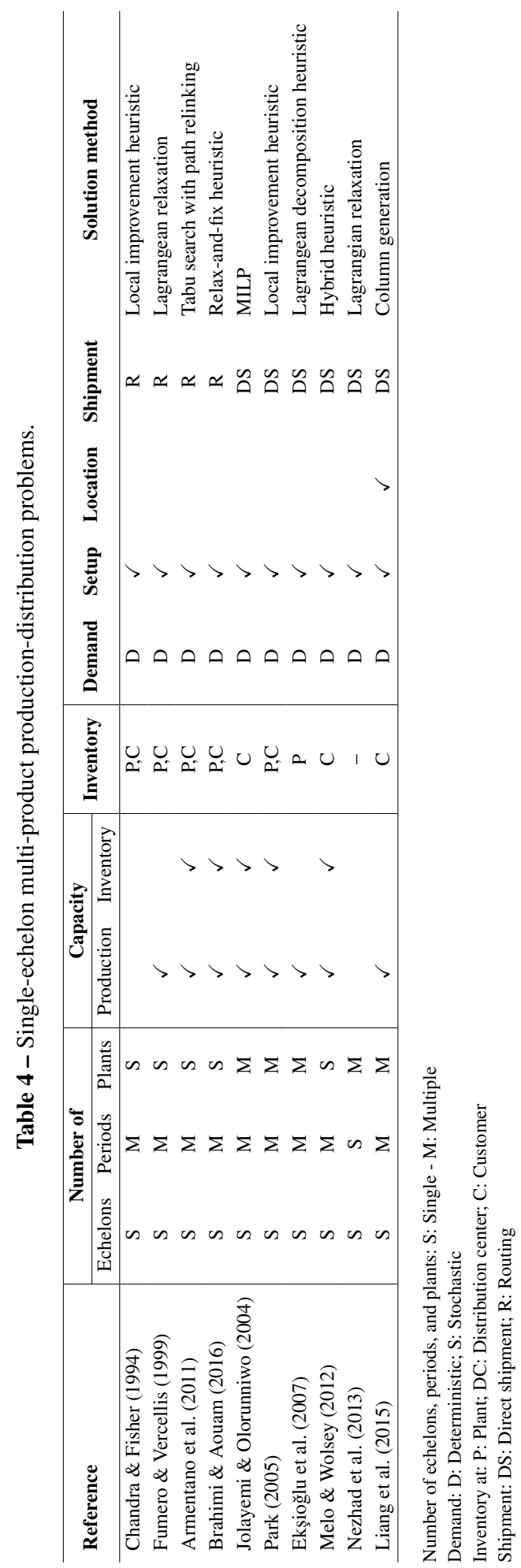




\subsection{Multi-echelon models}

Due to the complexity of multi-product, multi-echelon integrated production-distribution problems, the main delivery method considered in models from this category is the direct shipment. However, it is interesting to note that mostly exact methods are proposed to solve these problems. Lagrangean approaches are used in Pirkul \& Jayaraman (1996); Barbarosoğlu \& Özgür (1999); Jayaraman \& Pirkul (2001); Elhedhli \& Goffin (2005). Pirkul \& Jayaraman (1996) applied a Lagrangean relaxation based heuristic to solve a production-distribution integrated with facility location-allocation problem. All customers are served from a warehouse selected among a number of available ones. Barbarosoğlu \& Özgür (1999) decompose the production-distribution problem into two smaller and easier to solve subporblems. Jayaraman \& Pirkul (2001) enriched the problem studied in Pirkul \& Jayaraman (1996) by adding the procurement decisions. They had a real case to solve by their proposed Lagrangean approach, however, they generated first several random instances and compared the performance of the method against the optimal solutions obtained by a commercial solver. Finally, Elhedhli \& Goffin (2005) applied a Lagrangean relaxation incorporated with the interior-point and branch-and-bound methods to solve a network design problem dealing with production-distribution decisions. On another production-distribution network design problem, Correia et al. (2013) proposed a branch-and-cut algorithm to solve randomly generated instances.

Several other solutions algorithms are also proposed in the literature to solve different variants of the production-distribution problem. For example, De Matta et al. (2015) examined an integrated problem in which the delivery method needs to be decided between the direct shipment or consolidated delivery offered by a third party logistics company. They applied a Benders decomposition method to solve this problem. Darvish \& Coelho (2018) introduced a rich integrated production-distribution problem motivated by an industrial collaboration. Their model incorporated delivery due dates and flexible supply chain network design features. However, their main contribution remained on quantifying the advantages of supply chain integration by comparing results obtained from several sequential procedures with the integrated ones. In order to solve large size instances of the problem, they also developed a matheuristic based on the variable neighborhood search method.

To conclude this section, we review papers that address routing decisions in multi- product multi-echelon models. Hein \& Almeder (2016) integrated supply vehicle routing and production planning decisions. The variable production costs were not considered in their model which minimized the setup, inventory, and distribution costs. They highlighted the advantages of the integrated approach and conclude that in just-in-time approaches, the potential savings are even higher. Inspired by a meat production plant, Neves-Moreira et al. (2019) solved a large PRP with delivery time windows. In their three-phase solution algorithm, first, they simplified some decisions in order to reduce the size of the problem. Then they applied a decomposition approach, and finally, a fixed-and-optimize matheurtistic was applied. The performance of this solution algorithm was tested on several available benchmark instances from the literature. Moreover, 
the results obtained from applying the integrated optimization approach to a case study showed $21.73 \%$ saving compared to the company's solutions.

A summary of the integrated production-distribution models with multiple products and multiple echelon is presented in Table 5.

\section{DISCUSSIONS AND FURTHER RESEARCH DIRECTIONS}

Due to the importance of production-distribution problems in research and practice, they are vastly studied in the OR literature. Findings from several studies confirm the many benefits of the integrated approach in supply chain decision making. We have also identified a rapidly growing interest in these approaches, a large number of papers, especially on the PRP, are published recently. However, we have observed that this body of research lacks a unifying framework and is highly fragmented.

The integrated problems we reviewed in this paper advanced significantly the state of the literature. However, the potential of integrated optimization is not yet fully explored and several gaps already exists that further research can fill. In order to better analyze the current research hotspots and identify the future research direction, we pinpoint several main trends and their respective research avenues.

- Holistic supply chain planning: several integrated problem are already introduced in the literature, but a holistic supply chain planning approach is still far from being realized.

Decisions from different supply chain functions: location and procurement decisions of the supply chains can also be integrated into the production-distribution models.

Circular economy movement: in the past decade, enhancing the circular economy has been motivated. Hence, its integration with production-distribution decisions seems to be the next logical step.

Eigenmodel: In public transportation planning, Schöbel (2017) proposed a so-called eigenmodel ("model of itself", see Möhring et al. (1995)) for integrated line planning, timetabling and vehicle scheduling. This approach makes use of the fact that the integrated problem naturally consist of subproblems, i.e., the ones that are to be integrated, and solves them iteratively with previous solutions of some or all the subproblems fixed (a kind of neighborhood search). The benefit of such an approach is that the subproblems can be studied independently, their solution algorithms can be based on existing algorithms, and their specific structures can be exploited. Once the subproblems can be solved effectively, the eigenmodel iterates over the different subproblems until some stopping criterion is reached. A potential future direction could be to explore this idea within the context of integrated supply chain planning.

- Supply chain digitalization: leveraging the potential of information technology, companies are propelled into the digital supply chain era. 


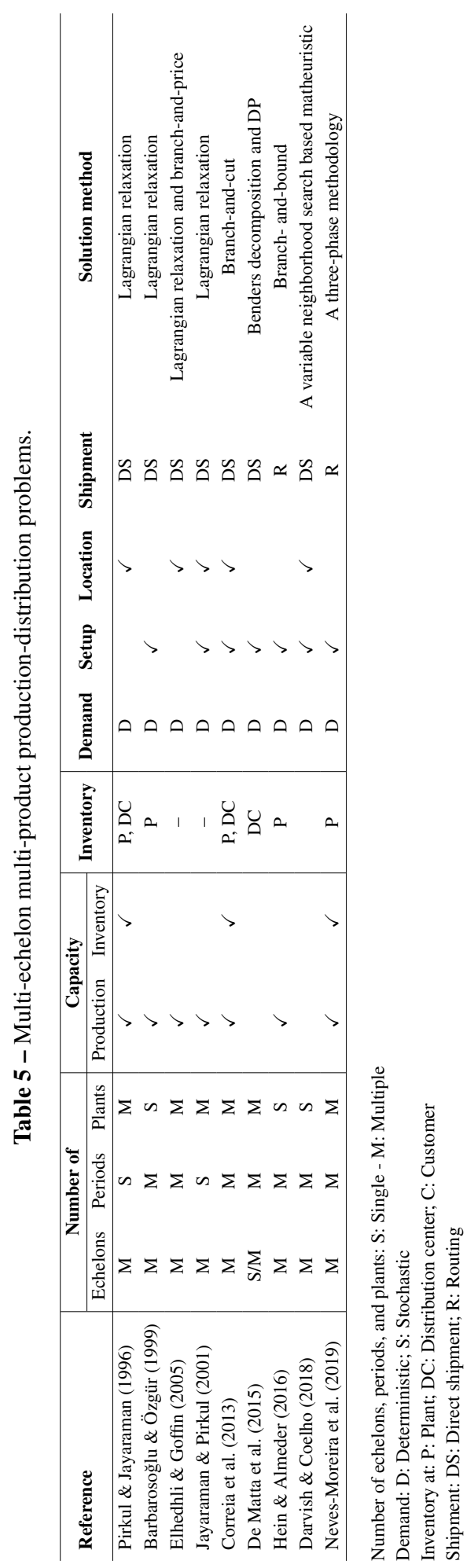

Pesquisa Operacional, Vol. 41 (s1), 2021: e246080 
Real-time decision making: collecting and using real-time information for decision making is a very common practice these days in many industries. However, due to the complexity involved in solving production-distribution problems, considering realtime, real-time production-distribution decision making is yet to be explored.

Data-driven integrated models: the amount of data generated and stored has dramatically increased. The collected data needed to be processed and analyzed first before being used in optimization problems. Increased data granularity comes at a cost of more complex models. Therefore, production-distribution problems have mainly focused on randomly generated instances.

\section{- Sustainable supply chains:}

Environmental issues: incorporating environmental issues in optimization research is receiving growing attention. However, the current integrated optimization literature has been mainly focused on increasing the service level and reducing the total costs.

- Real world application: The applications of the studies cited in the previous section. A great number of papers published on the production-distribution integration use numerical experiments on randomly generated instances to test the performance of the solution algorithms. Real-world applications of the models and algorithms are still lacking in the literature.

Demand uncertainty: only very few studies have considered the stochasticity of the dynamic environments. The majority of studies assume the demand to be known in advance, and plan the production and distributions based on this assumption. A future research opportunity would be to investigate stochastic production-distribution integration.

Decision making under flexible network design: Speranza (2018) identifies the flexible network design as a new trend and research opportunity in logistics. Most of the research integrating production and distribution considers fixed settings. For example, the upstream and downstream supply partners are always known and fixed. The location of facilities rarely changes during the planning horizon.

More realistic cost structures: in most studies costs are linear and no economies of scale arise. Economies of scale in production, transportation and inventory could also be investigated in future research.

Multiple products, multi-echelon settings: as the number of products, echelons, facilities, and periods increase, problems become more complex and therefore, more difficult to solve. Hence, most papers mainly considered a single echelon and singleproduct setting. A future research avenue would be to develop fast and efficient methods to solve multi-echelon, multi-product, large instances of the integrated production and distribution problem. 
- Effective exact algorithms: integrated lot sizing with distribution problems are mainly solved exploiting decomposition or relaxation techniques. The set of binary decisions are considered first and then, one solves a network flow problem. Future research could develop faster and more efficient methods to solve large instances of LSPs (Absi et al., 2014).

\section{CONCLUSIONS}

This paper provides a comprehensive, but not exhaustive overview of the broad literature on the integrated supply chain optimization, with the main focus on the integration of production and distribution decisions. Figure 4 provides a general overview on the papers studied.

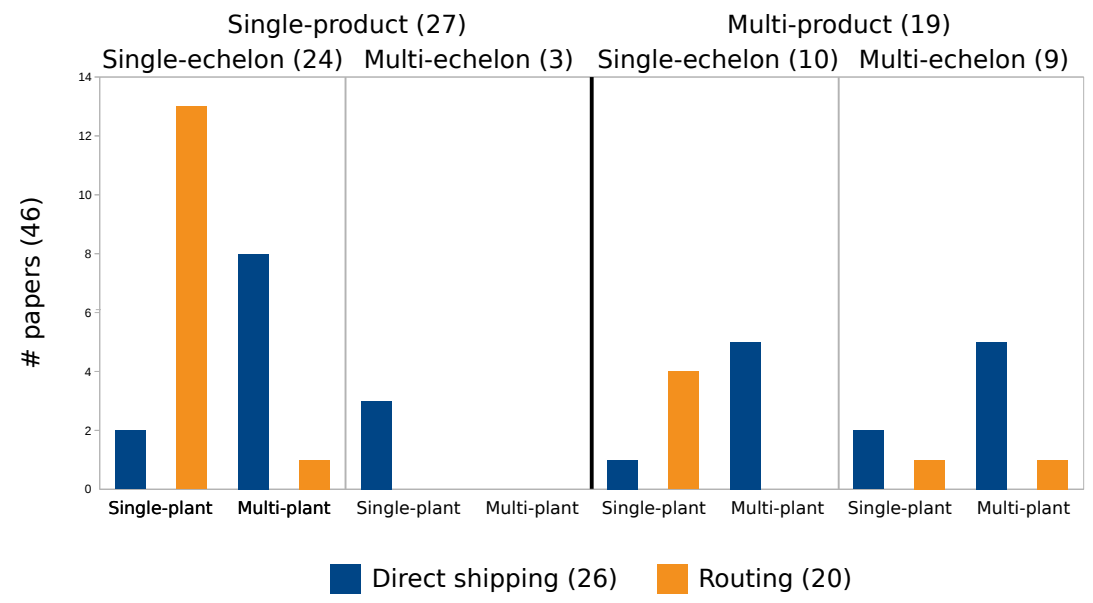

Figure 4 - A general overview of the paper.

We have classified the papers presented in the literature based on different characteristics, including the number of products, echelons, periods and plants considered, the presence of capacity constraints, setup costs, location decisions in their mathematical model, the shipment methods, and finally type of demand. We have also reviewed their solution algorithms and suggested some interesting venues for the future research.

\section{Acknowledgements}

This project was partly funded by the Canadian Natural Sciences and Engineering Research Council (NSERC) under grants 2020-00401, 2019-00094, and 2018-03712. This support is greatly acknowledged. 


\section{References}

[1] Absi N, Archetti C, Dauzère-Pérès S \& Feillet D. 2014. A two-phase iterative heuristic approach for the production routing problem. Transportation Science, 49(4): 784-795.

[2] Adulyasak Y, Cordeau JF \& Jans R. 2012. Optimization-based adaptive large neighborhood search for the production routing problem. Transportation Science, 48(1): $20-45$.

[3] Adulyasak Y, Cordeau JF \& Jans R. 2014. Formulations and Branch-and-Cut Algorithms for Multi-Vehicle Production and Inventory Routing Problems. INFORMS Journal on Computing, 26(1): 103-120.

[4] Adulyasak Y, Cordeau JF \& JAns R. 2015. The production routing problem: A review of formulations and solution algorithms. Computers \& Operations Research, 55 : $141-152$.

[5] Ahuja R, Huang W, Romeijn H \& Morales D. 2007. A heuristic approach to the multi-period single-sourcing problem with production and inventory capacities and perishability constraints. INFORMS Journal on Computing, 19(1): 14-26.

[6] Akbalik A \& Penz B. 2011. Comparison of just-in-time and time window delivery policies for a single-item capacitated lot sizing problem. International Journal of Production Research, 49(9): 2567-2585.

[7] Almouhanna A, Quintero-Araujo CL, Panadero J, Juan AA, Khosravi B \& Ouelhadj D. 2020. The location routing problem using electric vehicles with constrained distance. Computers \& Operations Research, 115: 104864.

[8] AmiRi A. 2006. Designing a distribution network in a supply chain system: Formulation and efficient solution procedure. European Journal of Operational Research, 171(2): $567-576$.

[9] Andersson H, Hoff A, Christiansen M, Hasle G \& Løkketangen A. 2010. Industrial aspects and literature survey: Combined inventory management and routing. Computers \& Operations Research, 37(9): 1515-1536.

[10] Archetti C, Bertazzi L, Paletta G \& Speranza M. 2011. Analysis of the maximum level policy in a production-distribution system. Computers \& Operations Research, 12(38): 1731-1746.

[11] Armentano V, Shiguemoto A \& Løknetangen A. 2011. Tabu search with path relinking for an integrated production-distribution problem. Computers \& Operations Research, 38(8): 1199-1209. 
[12] Axs ÄTER S. 2015. Inventory Control. chap. Multi-Echelon Systems: Lot Sizing, pp. 171189. Cham: Springer International Publishing.

[13] Barany I, VAn Roy T \& Wolsey L. 1984. Strong formulations for multi-item capacitated lot sizing. Management Science, 30(10): 1255-1261.

[14] BArbarosoĞLU G \& ÖZGÜR D. 1999. Hierarchical design of an integrated production and 2-echelon distribution system. European Journal of Operational Research, 118(3): 464-484.

[15] BARD J \& NANANUKUL N. 2009a. Heuristics for a multiperiod inventory routing problem with production decisions. Computers \& Industrial Engineering, 57(3): 713-723.

[16] BARD J \& NANANUKUL N. 2009b. The integrated production-inventory-distributionrouting problem. Journal of Scheduling, 12(3): 257-280.

[17] BARD J \& NANANUKul N. 2010. A branch-and-price algorithm for an integrated production and inventory routing problem. Computers \& Operations Research, 37(12): 2202-2217.

[18] Bean JW, Devpura A, O’Brien M \& Shirodkar S. 2005. Optimizing SupplyChain Planning. Intel Technology Journal, 9(3).

[19] Belo-Filho M, Amorim P \& Almada-Lobo B. 2015. An adaptive large neighbourhood search for the operational integrated production and distribution problem of perishable products. International Journal of Production Research, 53(20): 6040-6058.

[20] Boudia M, LOUly M \& PRINS C. 2007. A reactive GRASP and path relinking for a combined production-distribution problem. Computers \& Operations Research, 34(11): 3402-3419.

[21] Boudia M, Louly M \& PRins C. 2008. Fast heuristics for a combined production planning and vehicle routing problem. Production Planning and Control, 19(2): 85-96.

[22] Boudia M \& PRins C. 2009. A memetic algorithm with dynamic population management for an integrated production-distribution problem. European Journal of Operational Research, 195(3): 703-715.

[23] Boventer E. 1961. The relationship between transportation costs and location rent in transportation problems. Journal of Regional Science, 3(2): 27-40.

[24] BRAhimi N \& Aouam T. 2016. Multi-item production routing problem with backordering: a MILP approach. International Journal of Production Research, 54(4): 1076-1093. 
[25] Brahimi N, Dauzère-PÉrès S, Najid N \& Nordli A. 2006. Single item lot sizing problems. European Journal of Operational Research, 168(1): 1-16.

[26] BRandeau M \& ChiU S. 1989. An overview of representative problems in location research. Management Science, 35(6): 645-674.

[27] Buschiühl L, Sahling F, Helber S \& Tempelmeier H. 2010. Dynamic capacitated lot-sizing problems: a classification and review of solution approaches. $O R$ Spectrum, 32(2): 231-261.

[28] Campbell A, Clarke L, Kleywegt A \& Savelsbergh M. 1998. The inventory routing problem. In: CRAINIC T (Ed.), Fleet Management and Logistics. pp. 95-113. Springer.

[29] CARTER C \& Rogers D. 2008. A framework of sustainable supply chain management: moving toward new theory. International Journal of Physical Distribution \& Logistics Management, 38(5): 360-387.

[30] Chandra P \& Fisher M. 1994. Coordination of production and distribution planning. European Journal of Operational Research, 72(3): 503-517.

[31] Chen ZL. 2004. Integrated Production and Distribution Operations. In: Simchi-Levi D, WU SD \& SHEN ZJ (Eds.), Handbook of Quantitative Supply Chain Analysis. pp. 711-745. Boston, MA: Springer US.

[32] CHEN ZL. 2010. Integrated production and outbound distribution scheduling: review and extensions. Operations Research, 58(1): 130-148.

[33] Christopher M. 2016. Logistics \& Supply Chain Management. Harlow: Financial Times/Pearson Education.

[34] Coelho L, Cordeau JF \& Laporte G. 2014. Thirty Years of Inventory Routing. Transportation Science, 48(1): 1-19.

[35] Coelho LC, Renaud J \& LAporte G. 2016. Road-based goods transportation: a survey of real-world logistics applications from 2000 to 2015. INFOR: Information Systems and Operational Research, 54(2): 79-96.

[36] Correia i, Melo T \& Saldanha da Gama F. 2013. Comparing classical performance measures for a multi-period, two-echelon supply chain network design problem with sizing decisions. Computers \& Industrial Engineering, 64(1): 366-380.

[37] Darvish M, Archetti C, Coelho LC \& Speranza MG. 2019. Flexible twoechelon location routing problem. European Journal of Operational Research, 277(3): 1124-1136. 
[38] Darvish M \& Coelho LC. 2018. Sequential versus integrated optimization: Production, location, inventory control, and distribution. European Journal of Operational Research, 268(1): 203-214.

[39] Darvish M, Larrain H \& Coelho L. 2016. A dynamic multi-plant lot-sizing and distribution problem. International Journal of Production Research, 54(22): 6707-6717.

[40] Daskin M, Coullard C \& Shen ZJ. 2002. An inventory-location model: Formulation, solution algorithm and computational results. Annals of Operations Research, 110(1-4): 83-106.

[41] De Matta R, Hsu V \& Li CL. 2015. Coordinated production and delivery for an exporter. IIE Transactions, 47(4): 373-391.

[42] Desrochers M, Desrosiers J \& Solomon M. 1992. A new optimization algorithm for the vehicle routing problem with time windows. Operations Research, 40(2): 342-354.

[43] Díaz-Madroñero M, Peidro D \& Mula J. 2015. A review of tactical optimization models for integrated production and transport routing planning decisions. Computers \& Industrial Engineering, 88: 518-535.

[44] DreXl M \& Schneider M. 2015. A survey of variants and extensions of the locationrouting problem. European Journal of Operational Research, 241(2): 283-308.

[45] Eksioglu B, Vural A \& Reisman A. 2009. The vehicle routing problem: A taxonomic review. Computers \& Industrial Engineering, 57(4): 1472-1483.

[46] EKşıOĞLU S, EkşıOĞLU B \& ROMEIJN H. 2007. A Lagrangean heuristic for integrated production and transportation planning problems in a dynamic, multi-item, two-layer supply chain. IIE Transactions, 39(2): 191-201.

[47] EkşioĞLU S, Romeijn H \& PARdalos P. 2006. Cross-facility management of production and transportation planning problem. Computers \& Operations Research, 33(11): 3231-3251.

[48] Elhedhli S \& GofFin JL. 2005. Efficient production-distribution system design. Management Science, 51(7): 1151-1164.

[49] ERLEnKotter D. 1978. A dual-based procedure for uncapacitated facility location. Operations Research, 26(6): 992-1009.

[50] Fahimnia B, Farahani R, Marian R \& Luong L. 2013. A review and critique on integrated production-distribution planning models and techniques. Journal of Manufacturing Systems, 32(1): 1-19.

[51] Farahani R, Asgari N, Heidari N, Hosseininia M \& Goh M. 2012. Covering problems in facility location: A review. Computers \& Industrial Engineering, 62(1): 368407. 
[52] Farahani R, Hekmatfar M, Fahimnia B \& Kazemzadeh N. 2014. Hierarchical facility location problem: Models, classifications, techniques, and applications. Computers \& Industrial Engineering, 68: 104-117.

[53] Farahani R, Rashidi Bajgan H, Fahimnia B \& Kaviani M. 2015. Locationinventory problem in supply chains: a modelling review. International Journal of Production Research, 53(12): 3769-3788.

[54] Florian M, Lenstra J \& Rinnooy KAn A. 1980. Deterministic production planning: Algorithms and complexity. Management Science, 26(7): 669-679.

[55] Francis R, MCGinnis L \& White J. 1983. Locational analysis. European Journal of Operational Research, 12(3): 220-252.

[56] Fumero F \& VerCellis C. 1999. Synchronized development of production, inventory and distribution schedules. Transportation Science, 33(3): 330-340.

[57] Gendreau M, Hertz A \& Laporte G. 1994. A tabu search heuristic for the vehicle routing problem. Management Science, 40(10): 1276-1290.

[58] Glock C, Grosse E \& Ries J. 2014. The lot sizing problem: A tertiary study. International Journal of Production Economics, 155: 39-51.

[59] Gruson M, BAzRAfshan M, Cordeau JF \& JAns R. 2019. A comparison of formulations for a three-level lot sizing and replenishment problem with a distribution structure. Computers \& Operations Research, 111: 297-310.

[60] Hein F \& Almeder C. 2016. Quantitative insights into the integrated supply vehicle routing and production planning problem. International Journal of Production Economics, 177: 66-76.

[61] Hugos M. 2011. Essentials of supply chain management. John Wiley \& Sons.

[62] HwANG HC. 2010. Economic lot-sizing for integrated production and transportation. Operations Research, 58(2): 428-444.

[63] Hwang HC, Ahn HS \& Kaminsky P. 2016. Algorithms for the two-stage productioncapacitated lot-sizing problem. Journal of Global Optimization, 65(4): 777-799.

[64] Hwang HC \& KANG J. 2016. Two-phase algorithm for the lot-sizing problem with backlogging for stepwise transportation cost without speculative motives. Omega, 59: $238-250$.

[65] Jans R \& Degraeve Z. 2007. Meta-heuristics for dynamic lot sizing: A review and comparison of solution approaches. European Journal of Operational Research, 177(3): $1855-1875$. 
[66] Jans R \& Degraeve Z. 2008. Modeling industrial lot sizing problems: a review. International Journal of Production Research, 46(6): 1619-1643.

[67] JAyaraman V \& Pirkul H. 2001. Planning and coordination of production and distribution facilities for multiple commodities. European Journal of Operational Research, 133(2): 394-408.

[68] Jolayemi J \& Olorunniwo F. 2004. A deterministic model for planning production quantities in a multi-plant, multi-warehouse environment with extensible capacities. International Journal of Production Economics, 87(2): 99-113.

[69] KARAOĞLAN İ \& KeSEN S. 2017. The coordinated production and transportation scheduling problem with a time-sensitive product: a branch-and-cut algorithm. International Journal of Production Research, 55(2): 536-557.

[70] Karimi B, Ghomi S \& Wilson J. 2003. The capacitated lot sizing problem: a review of models and algorithms. Omega, 31(5): 365-378.

[71] Klose A \& Drexl A. 2005. Facility location models for distribution system design. European Journal of Operational Research, 162(1): 4-29.

[72] Koç Ç, Bektaş T, Jabali O \& Laporte G. 2016. Thirty years of heterogeneous vehicle routing. European Journal of Operational Research, 249(1): 1-29.

[73] Lahyani R, Khemakhem M \& Semet F. 2015. Rich vehicle routing problems: From a taxonomy to a definition. European Journal of Operational Research, 241(1): 1-14.

[74] LAMBerT DM \& ENZ MG. 2017. Issues in supply chain management: Progress and potential. Industrial Marketing Management, 62: 1-16.

[75] LAPORTE G. 1992. The vehicle routing problem: An overview of exact and approximate algorithms. European Journal of Operational Research, 59(3): 345-358.

[76] LAPORTE G. 2009. Fifty years of vehicle routing. Transportation Science, 43(4): 408416.

[77] Laporte G, Nickel S \& Saldanha-da Gama F. 2019. Introduction to location science. In: Location science. pp. 1-21. Springer.

[78] Lei L, LiU S, Ruszczynski A \& PARK S. 2006. On the integrated production, inventory, and distribution routing problem. IIE Transactions, 38(11): 955-970.

[79] Liang Z, He Y, Wu T \& Zhang C. 2015. An informative column generation and decomposition method for a production planning and facility location problem. International Journal of Production Economics, 170: 88-96. 
[80] Maes J, McClain J \& Van Wassenhove L. 1991. Multilevel capacitated lotsizing complexity and LP-based heuristics. European Journal of Operational Research, 53(2): 131-148.

[81] Meinecke C \& Scholz-Reiter B. 2014. A representation scheme for integrated production and outbound distribution models. International Journal of Logistics Systems and Management, 18(3): 283-301.

[82] Melo M, Nickel S \& Saldanha da Gama F. 2006. Dynamic multi-commodity capacitated facility location: a mathematical modeling framework for strategic supply chain planning. Computers \& Operations Research, 33(1): 181-208.

[83] Melo M, Nickel S \& Saldanha da Gama F. 2009. Facility location and supply chain management-A review. European Journal of Operational Research, 196(2): 401412.

[84] Melo R \& Wolsey L. 2012. MIP formulations and heuristics for two-level productiontransportation problems. Computers \& Operations Research, 39(11): 2776-2786.

[85] Möhring RH, Müller R \& RAdermacher FJ. 1995. Advanced DSS for scheduling: software engineering aspects and the role of Eigenmodels. Annals of Operations Research, 55: 453-469.

[86] MoIN N \& SALHI S. 2007. Inventory routing problems: a logistical overview. Journal of the Operational Research Society, 58(9): 1185-1194.

[87] Mula J, Peidro D, Díaz-Madroñero M \& Vicens E. 2010. Mathematical programming models for supply chain production and transport planning. European Journal of Operational Research, 204(3): 377-390.

[88] Mustafa Kamal M \& IRAni Z. 2014. Analysing supply chain integration through a systematic literature review: a normative perspective. Supply Chain Management: An International Journal, 19(5/6): 523-557.

[89] NAgy G \& Salhi S. 2007. Location-routing: Issues, models and methods. European Journal of Operational Research, 177(2): 649-672.

[90] Neves-Moreira F, Almada-Lobo B, Cordeau JF, Guimarães L \& Jans R. 2019. Solving a large multi-product production-routing problem with delivery time windows. Omega, 86: 154-172.

[91] Nezhad A, Manzour H \& S ALhi S. 2013. Lagrangian relaxation heuristics for the uncapacitated single-source multi-product facility location problem. International Journal of Production Economics, 145(2): 713-723.

[92] OWEN S \& DASKIN M. 1998. Strategic facility location: A review. European Journal of Operational Research, 111(3): 423-447. 
[93] PARK Y. 2005. An integrated approach for production and distribution planning in supply chain management. International Journal of Production Research, 43(6): 1205-1224.

[94] Pillac V, Gendreau M, Guéret C \& Medaglia A. 2013. A review of dynamic vehicle routing problems. European Journal of Operational Research, 225(1): 1-11.

[95] Pirkul H \& JAYARAman V. 1996. Production, transportation, and distribution planning in a multi-commodity tri-echelon system. Transportation Science, 30(4): 291-302.

[96] Power D. 2005. Supply chain management integration and implementation: a literature review. Supply Chain Management: An International Journal, 10(4): 252-263.

[97] Prodhon C \& Prins C. 2014. A survey of recent research on location-routing problems. European Journal of Operational Research, 238(1): 1-17.

[98] Psaraftis H, Wen M \& Kontovas C. 2016. Dynamic vehicle routing problems: Three decades and counting. Networks, 67(1): 3-31.

[99] ReVelle C \& LApORTE G. 1996. The plant location problem: new models and research prospects. Operations Research, 44(6): 864-874.

[100] Ritzinger U, Puchinger J \& Hartl R. 2016. A survey on dynamic and stochastic vehicle routing problems. International Journal of Production Research, 54(1): 215-231.

[101] Robinson P, Narayanan A \& Sahin F. 2009. Coordinated deterministic dynamic demand lot-sizing problem: A review of models and algorithms. Omega, 37(1): 3-15.

[102] Romeijn H, Sharkey T, Shen ZJM \& Zhang J. 2010. Integrating facility location and production planning decisions. Networks, 55(2): 78-89.

[103] Ruokokoski M, Solyali O, Cordeau JF, Jans R \& Süral H. 2010. Efficient formulations and a branch-and-cut algorithm for a production-routing problem. Les Cahiers du GERAD G-2010-66, Tech. Rep., .

[104] ŞAHIN G \& SÜRAL H. 2007. A review of hierarchical facility location models. Computers \& Operations Research, 34(8): 2310-2331.

[105] Sambasivan M \& SCHMidT C. 2002. A heuristic procedure for solving multiplant, mutli-item, mutli-period capacitated lot-sizing problems. Asia-Pacific Journal of Operational Research, 19(1): 87-105.

[106] Sarmiento A \& NAgi R. 1999. A review of integrated analysis of productiondistribution systems. IIE Transactions, 31(11): 1061-1074.

[107] Schenekemberg CM, Scarpin CT, Pécora JR JE, Guimarães TA \& CoElho LC. 2020. The two-echelon production-routing problem. European Journal of Operational Research, forthcoming. 
[108] Schmidt CE, Silva ACL, Darvish M \& Coelho LC. 2019. The time-dependent location-routing problem. Transportation Research Part E: Logistics and Transportation Review, 128(C): 293-315.

[109] SCHNEIDER M \& DREXL M. 2017. A survey of the standard location-routing problem. Annals of Operations Research, 259(1-2): 389-414.

[110] SchöBEL A. 2017. An eigenmodel for iterative line planning, timetabling and vehicle scheduling in public transportation. Transportation Research Part C: Emerging Technologies, 74: 348-365.

[111] Senoussi A, Dauzère-Pérès S, Brahimi N, Penz B \& Mouss NK. 2018. Heuristics based on genetic algorithms for the capacitated multi vehicle production distribution problem. Computers \& Operations Research, 96: 108-119.

[112] Sharkey T, Geunes J, RH E \& Shen ZJ. 2011. Exact algorithms for integrated facility location and production planning problems. Naval Research Logistics, 58(5): 419-436.

[113] Shen ZJ, Coullard C \& Daskin M. 2003. A joint location-inventory model. Transportation Science, 37(1): 40-55.

[114] SNYDER L. 2006. Facility location under uncertainty: a review. IIE Transactions, 38(7): $547-564$.

[115] Solyali O \& SÜRAL H. 2017. A multi-phase heuristic for the production routing problem. Computers \& Operations Research, 87: 114 - 124.

[116] Speranza M. 2018. Trends in transportation and logistics. European Journal of Operational Research, 264(3): 830-836.

[117] StAdTLER H. 2005. Supply chain management and advanced planning-basics, overview and challenges. European Journal of Operational Research, 163(3): 575-588.

[118] Taillard É, Badeau P, Gendreau M, Guertin F \& Potvin JY. 1997. A tabu search heuristic for the vehicle routing problem with soft time windows. Transportation Science, 31(2): 170-186.

[119] Tотн P \& Vigo D (Eds.). 2014. Vehicle Routing. Monographs on Discrete Mathematics and Applications. Philadelphia: MOS-SIAM Series on Optimization.

[120] Trochu J, Chanane A \& Ouhimmou M. 2019. A two-stage stochastic optimization model for reverse logistics network design under dynamic suppliers' locations. Waste Management, 95: 569-583.

[121] van Hoesel S, Romeijn H, Morales D \& Wagelmans A. 2005. Integrated lot sizing in serial supply chains with production capacities. Management Science, 51(11): $1706-1719$. 
[122] Vogel T, Almada-Lobo B \& Almeder C. 2017. Integrated versus hierarchical approach to aggregate production planning and master production scheduling. OR Spectrum, 39(1): 193-229.

[123] Wagner H \& Whitin T. 1958. Dynamic version of the economic lot size model. Management Science, 5(1): 89-96.

\section{How to cite}

DARVish M, Kidd MP, COelho LC \& Renaud J. 2021. Integrated production-distribution systems: trends and perspectives. Pesquisa Operacional, 41 (s1): e246080. doi: 10.1590/01017438.2021.041s1.00246080. 